\title{
Retrovirus-induced Feline Pure Red Cell Aplasia \\ Hematopoietic Progenitors Are Infected with Feline Leukemia Virus and Erythroid Burst-forming Cells Are Uniquely Sensitive to Heterologous Complement
}

Janis L. Abkowitz, Richard D. Holly, and Chris K. Grant

Division of Hematology, Department of Medicine, University of Washington, Seattle, Washington 98195; and Pacific Northwest

Research Foundation, Seattle, Washington 98020

\begin{abstract}
Feline leukemia virus subgroup C/Sarma (FeLV-C) induces pure red cell aplasia (PRCA) in cats. Just before the onset of anemia, erythroid colony-forming cells (CFU-E) become undetectable in marrow culture, yet normal frequencies of erythroid burst-forming cells (BFU-E)- and granulocyte-macrophage colony-forming cells (CFU-GM) persist. To determine if erythroid progenitors were uniquely infected with retrovirus, marrow mononuclear cells from cats viremic with FeLV-C were labeled with monoclonal antibodies to $\mathrm{gp} 70$ and then analyzed with a fluorescence-activated cell sorter. Both erythroid and granulocyte-macrophage progenitors were among cells sorting positively, suggesting that infection of BFU-E alone did not result in PRCA. The results were confirmed by complement $\left(C^{\prime}\right)$ lysis studies using baby rabbit or guinea pig sera as sources of $C^{\prime}$. These studies also suggested that BFU-E from cats with PRCA were unusually sensitive to $C^{\prime}$ alone, without the addition of antibody. In further studies, we demonstrated that $\mathbf{C}^{\prime}$ activation was via the classical pathway and that $\mathbf{C}^{\prime}$ sensitivity was unique to BFU-E and not a property of CFU-E, CFU-GM, or progenitors that were capable of giving rise to BFU-E in suspension culture. As BFU-E from cats viremic with FeLV-A/Glasgow-1 or the Rickard strain of feline leukemia virus were not sensitive to $C^{\prime}$, this finding may relate to the pathogenesis of feline PRCA. We hypothesize that, in cats viremic with FeLV-C, the abnormal $C^{\prime}$ sensitivity of BFU-E leads to the absence of CFU-E and anemia.
\end{abstract}

\section{Introduction}

Feline leukemia virus (FeLV) ${ }^{1}$ is a replication-competent retrovirus that is associated with a wide spectrum of hematologic

Part of this study was presented at the meetings of the American Society of Hematology, December 1985 , and was also published in abstract form (1985. Blood. 66:118a).

Address correspondence to Dr. Abkowitz, Division of Hematology, RM-10, Department of Medicine, University of Washington, Seattle, WA 98195. 1987.

Received for publication 8 August 1986 and in revised form 20 April

1. Abbreviations used in this paper: BFU-E, erythroid burst-forming cell; CFU-E, erythroid colony-forming cell; CFU-GM, granulocytemacrophage colony-forming cell; FACS, fluorescence-activated cell sorter; $\triangle F C S$, heat-inactivated fetal calf serum; FEA, feline embryonic fibroblasts; FeLV, feline leukemia virus; FeLV-C, FeLV subgroup C/ Sarma; PNH, paroxysmal nocturnal hemoglobinuria; PRCA, pure red cell aplasia.

J. Clin. Invest.

(c) The American Society for Clinical Investigation, Inc. $0021-9738 / 87 / 10 / 1056 / 08 \$ 2.00$

Volume 80, October 1987, 1056-1063 disorders in cats including leukemia, lymphoma, myelodysplastic syndromes, immunosuppression, and nonregenerative anemia (1-3). In the laboratory, cats infected with FeLV subgroup C/Sarma (FeLV-C) develop pure red cell aplasia (PRCA) characterized by severe anemia, reticulocytopenia, and the absence of hemoglobinized cells in the marrow (4-6). Despite this abnormality in erythropoiesis, granulocytic and megakaryocytic morphology and maturation are normal. When marrow from cats with PRCA is cultured in vitro, no erythroid colonies (from erythroid colony-forming cells [CFU-E]) are detected. However, normal numbers of erythroid bursts (from erythroid burst-forming cells [BFU-E]) persist, implying that BFU-E can differentiate in vitro to the hemoglobinized cells comprising erythroid bursts but not in vivo to CFU-E (6).

Previously, we investigated if cellular or humoral interactions were responsible for the PRCA in FeLV-C-infected cats. Our studies failed to implicate $\mathrm{T}$ lymphocytes or circulating antibodies in the pathogenesis of the disease (7). In other experiments, we showed that BFU-E from cats with PRCA have increased cell cycle kinetics and an altered response to hematopoietic growth factor(s) (8), suggesting that an abnormality intrinsic to BFU-E may lead to impaired differentiation and result in anemia. For this reason, we have investigated if erythroid progenitors were infected with FeLV-C using antibodies directed at the dominant virus envelope glycoprotein, gp70, which incorporates in the membrane of cells productively infected with retrovirus. Fluorescence-activated cell sorter (FACS) analysis using monoclonal antibodies to gp70 indicated that committed hematopoietic progenitors (BFU-E, CFU-E, and granulocyte-macrophage colony-forming cells [CFU-GM]) were infected with FeLV-C. When confirming these studies with complement $\left(C^{\prime}\right)$ lysis experiments, we found that BFU-E from cats with PRCA were uniquely sensitive to the lytic action of heterologous $\mathrm{C}^{\prime}$ in the absence of exogenous antibody.

\section{Methods}

General methods. The animals used for these studies were the female $F_{1}$ offspring of matings between Geoffroy and domestic cats (6). The protocols for infection, for obtaining and processing specimens, and for the assay of feline CFU-E-, BFU-E-, and CFU-GM-derived colonies in methylcellulose culture have been reported $(6,8)$. Unless specifically noted, cells were cultured in the presence of $0.5 \mathrm{U} / \mathrm{ml}$ of partially purified human urinary erythropoietin and a 5\% concentration of medium conditioned by feline embryonic fibroblasts (FEA) infected with FeLV-A/Glasgow-1 (9). The percentage of feline hematopoietic progenitors in active DNA synthesis was determined using the tritiated thymidine suicide technique as reported previously (8).

FACS studies. To determine if feline hematopoietic progenitors were infected with retrovirus, marrow mononuclear cells were labeled with affinity-purified monoclonal antibodies C11D8 and/or G13D8 to 
gp70 (10). For these studies, $10^{6}$ cells were incubated in $100 \mu \mathrm{l}$ Hanks' balanced salt solution (HBSS; Gibco, Grand Island, NY) containing $0.1 \%$ bovine serum albumin (BSA; Reheis Chemical Co., Scottsdale, AZ) with a total antibody concentration of $12.5 \mu \mathrm{g} / \mathrm{ml}$ for $45 \mathrm{~min}$ at $4^{\circ} \mathrm{C}$. Next, the cells were washed twice with $\mathrm{HBSS} / 0.1 \%$ BSA and incubated with $100 \mu \mathrm{l}$ of a 1:40 dilution of fluoresceinated goat antimouse IgG (light and heavy chain specific; Tago Inc., Burlington, CA). Cells were then washed before FACS study. For control experiments, an irrelevant monoclonal antibody to the murine lymphocyte determinant Thy 1.1 (obtained from Chris Badger, Fred Hutchinson Cancer Research Center, Seattle, WA), I9B4 (a monoclonal antibody that recognizes the gp70 of FeLV strains A and B, but not C [unpublished observations]), or alpha medium (Flow Laboratories, Inc., McLean, VA) was substituted for C11D8 and/or G13D8 in the first incubation step. As a positive control, marrow cells were incubated initially with monoclonal antibody No. 8, which recognizes an Ia-like determinant on feline lymphoid cells and hematopoietic progenitors (unpublished observations).

For FACS analysis, the positive cutoff was determined so that $1-4 \%$ of marrow cells treated with an irrelevant first antibody or alpha medium would sort positively. Cells in the positive and negative fractions were counted and then plated in methylcellulose culture, generally at a concentration of $2.5 \times 10^{4} \mathrm{cells} / \mathrm{ml}$.

Complement lysis studies. To confirm the FACS results, $\mathrm{C}^{\prime}$ lysis studies were performed. For these experiments, $10^{6}$ marrow mononuclear cells were incubated in $100 \mu \mathrm{l} \mathrm{HBSS} / 0.1 \%$ BSA for $1 \mathrm{~h}$ at room temperature with monoclonal antibodies C11D8 and G13D8 (final concentration, $6.25 \mu \mathrm{g} / \mathrm{ml}$ for each antibody), the $1 \mathrm{~h}$ at $37^{\circ} \mathrm{C}$ with baby rabbit serum as the source of $C^{\prime}(1: 1 \mathrm{vol} / \mathrm{vol}$; Pel Freeze Biologicals, Rogers, AR). The cells were then washed with HBSS, resuspended to their original volume with alpha medium, and plated in methylcellulose. Our preliminary studies confirmed that concurrent incubation with C11D8 and G13D8, which mark distinct epitopes of gp70, amplified the $C^{\prime}$ lysis effect (10). As controls for the $C^{\prime}$ lysis studies, marrow cells were incubated with heat-activated fetal calf serum ( $\triangle \mathrm{FCS}$; Reheis Chemical Co.), $\mathrm{C}^{\prime}$ alone, or antibodies alone.

For other studies, guinea pig serum (Cordis Laboratories, Miami, FL), C4-deficient guinea pig serum (Cordis Laboratories), or cat serum was used as a source of $C^{\prime}$. For some experiments, $C^{\prime}$ was preincubated with $20 \mathrm{mM}$ EDTA $\left(37^{\circ} \mathrm{C}\right.$ for $\left.5 \mathrm{~min}\right)$ or $10 \mathrm{mM}$ EGTA $\left(37^{\circ} \mathrm{C}\right.$ for 5 $\mathrm{min})$ then $5 \mathrm{mM} \mathrm{MgCl} 2$, or was heat-inactivated $\left(56^{\circ} \mathrm{C}\right.$ for $\left.30 \mathrm{~min}\right)$. Heat or EDTA inhibits $\mathrm{C}^{\prime}$ activation via either the classical or alternate pathways. With EGTA and $\mathrm{MgCl}_{2}$, the alternate pathway remains intact (11).

Studies with cat serum were also done under conditions that amplify the C'-mediated lysis of cells from patients with paroxysmal nocturnal hemoglobinuria (PNH). For these experiments, marrow mononuclear cells were obtained from Cat 64550 before it was infected, when it was viremic, but before the onset of anemia, and again when the cat had PRCA. Cells $\left(5 \times 10^{6} / \mathrm{ml}\right)$ were placed in $\triangle \mathrm{FCS}$ with $5 \%$ dimethyl sulfoxide (J. T. Baker Chemical Co., Phillipsburg, NH), frozen with a controlled-rate cell freezer (Union Carbide Corp., Indianapolis, IN), and stored in liquid nitrogen. Before use, the cells were thawed, washed twice with alpha medium containing $10 \% \triangle \mathrm{FCS}$, and resuspended in saline $\left(20 \times 10^{6}\right.$ cells $\left./ \mathrm{ml}\right)$. For a Ham test $(12), 5 \times 10^{5}$ cells were added to $90 \%$ fresh cat serum (obtained from a normal sibling), acidified with $0.2 \mathrm{M}$ hydrogen chloride to $\mathrm{pH} 6.6$, in a total volume of $250 \mu \mathrm{l}$. After a 1-h incubation at $37^{\circ} \mathrm{C}$, the cells were washed with HBSS, resuspended to the initial volume, and plated in methylcellulose culture. Heat-inactivated $\left(56^{\circ} \mathrm{C}, 30 \mathrm{~min}\right)$ acidified serum served as the control. For a sucrose hemolysis test (13), $5 \times 10^{5}$ cells were added to $90 \%$ isotonic sucrose $(92.4 \mathrm{~g} /$ liter; Mallinckrodt, Inc., St. Louis, MO) and $5 \%$ fresh cat serum in a final volume of $250 \mu \mathrm{l}$. After incubation at $37^{\circ} \mathrm{C}$ for $1 \mathrm{~h}$, the cells were washed with HBSS, resuspended to the initial volume, and plated in methylcellulose culture. Heat-inactivated serum served as a control. The response of the thawed cells to baby rabbit $C^{\prime}$ was similar to that seen in studies with fresh marrow mononuclear cells (data not shown). Specifically, $5 \%$ of detect- able BFU-E remained when these stored 64550 PRCA marrow mononuclear cells were exposed to baby rabbit $C^{\prime}$.

In additional experiments, we examined the relationship of the $\mathrm{C}^{\prime}$ sensitivity of BFU-E to cell cycle kinetics and retrovirus infection. Studies were performed on marrow from two normal cats before and after anemia was induced with $50 \mathrm{mg} / \mathrm{kg}$ phenylhydrazine (Sigma Chemical Co., St. Louis, MO) given intraperitoneally, followed by phlebotomy. Similar experiments were performed in two cats viremic with FeLV-A/Glasgow-1, which is not associated with hematological abnormalities (14), and in one cat viremic with the Rickard strain of FeLV $(15,16) .2$ mo after these studies, this cat developed a thymic lymphoma.

Suspension cultures. To determine if cells less differentiated than BFU-E were infected with FeLV-C or were sensitive to $C^{\prime}$, marrow mononuclear cells were treated as above with antibodies to $\mathrm{gp} 70$ or $\triangle \mathrm{FCS}$ and then $\mathrm{C}^{\prime}$ or $\triangle \mathrm{FCS}$. These cells were then resuspended to their initial volume and placed in suspension cultures containing $1 \mathrm{ml}$ of alpha medium with all the ingredients of methylcellulose culture except the methylcellulose (8). After a 2 -d incubation at $37^{\circ} \mathrm{C}$ in $4 \% \mathrm{CO}_{2}$ in air, residual cells were washed, resuspended in $1 \mathrm{ml}$ of alpha medium, and the frequencies of progenitors were assayed in methylcellulose.

Studies of gp70 binding to non-infected progenitor cells. To confirm that the expression of gp70 on the surface of a progenitor cell reflected FeLV infection and not the nonspecific binding of virus, viral protein, or immune complex to the cell membrane, $10^{6}$ normal marrow mononuclear cells were incubated at $37^{\circ} \mathrm{C}$ for $1 \mathrm{~h}$ with $200 \mu \mathrm{l}$ of supernatant obtained over a 24-h period from nearly confluent FEA infected with FeLV-C (6). After this incubation, cells were washed three times with HBSS. The cells were next incubated with C11D8 and G13D8 or $\triangle F C S$, followed by baby rabbit $C^{\prime}$ as described above, before being plated in methylcellulose. As a control, some cells were incubated initially with FEA supernatant. In additional studies designed to determine if immune complexes were adsorbed by hematopoietic cells, sera from cats with PRCA were used for the first incubation step.

\section{Results}

FACS studies. To determine if erythroid progenitors were uniquely infected with FeLV-C, FACS studies were performed with marrow from two cats with PRCA (four experiments), one cat viremic with FeLV-C before the onset of anemia (two experiments), and two normal cats (three experiments). A representative study of marrow from cat 64977 with PRCA is shown in Fig. 1. When marrow was incubated with control monoclonal antibody to Thy 1.1 (Fig. $1 A$ ), antibody I9B4 (Fig. $1 B$ ), or alpha medium (data not shown), and then with flouresceinated rabbit anti-mouse IgG, the distribution of flourescent cells did not change. When treated initially with monoclonal antibody No. 8 (Fig. $1 C$ ), $\sim 50 \%$ of cells were positive. Initial incubation with $\mathrm{C} 11 \mathrm{D} 8$ (Fig. $1 \mathrm{D}$ ) or G13D8 (not shown) shifted the entire fluorescence curve to the right, suggesting that most marrow cells express gp70.

In this experiment (Fig. 1), a cutoff for sorting was established such that $1 \%$ of cells treated with antibody to Thy 1.1 or antibody I9B4 would sort in the positive fraction. Results in Table I demonstrate that, for cat 64977 , most BFU-E and CFU-GM were sorted positively after exposure to C11D8. Similar results were obtained with marrow from cat 64550 (Table I) and increased frequencies of BFU-E and CFU-GM were seen among the $14 \%$ positive cells. To confirm the specificity of this finding, marrow cells from this cat that were treated with alpha medium in the first incubation step were arbitrarily sorted, such that $14 \%$ would be considered "posi- 


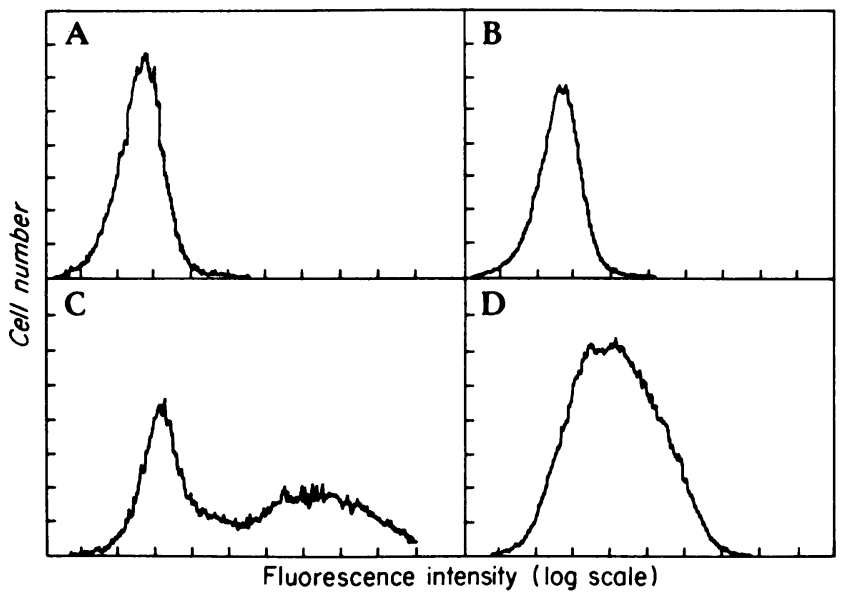

Figure 1. Flow cytometry study with marrow from a cat with PRCA. Marrow mononuclear cells were initially incubated with an irrelevant monoclonal antibody to the murine lymphocyte determinant Thy $1.1(A)$; monoclonal antibody $19 \mathrm{~B} 4$, which recognizes the $\mathrm{gp} 70$ of FeLV-A and B (but not FeLV-C) (B); monoclonal antibody No. 8, which labels an Ia-like determinant $(C)$; or monoclonal antibody C11D8, which recognizes the gp70 of FeLV-C $(D)$. The immunofluorescence curve in $D$ is shifted to the right, suggesting that most marrow cells expressed gp70.

tive." There was no increase in the frequency of BFU-E or CFU-GM in this fraction (Table I).

In additional studies, marrow cells from two normal cats were treated with alpha medium, monoclonal antibody to Thy 1.1, or antibodies C11D8 and G13D8 before incubation with the fluoresceinated second antibody and FACS analysis. The fluorescence distribution curves were identical in these studies (data not shown), suggesting that a determinant antigenically similar to gp70 was not present on normal cells.

Cat 65707 was studied 4 wk after inoculation with FeLVC. At that time, the fluorescence distribution curve had two peaks, suggesting that a subset of cells expressed gp70 (Fig. 2 A). FACS analysis (Table I) demonstrated that CFU-E,

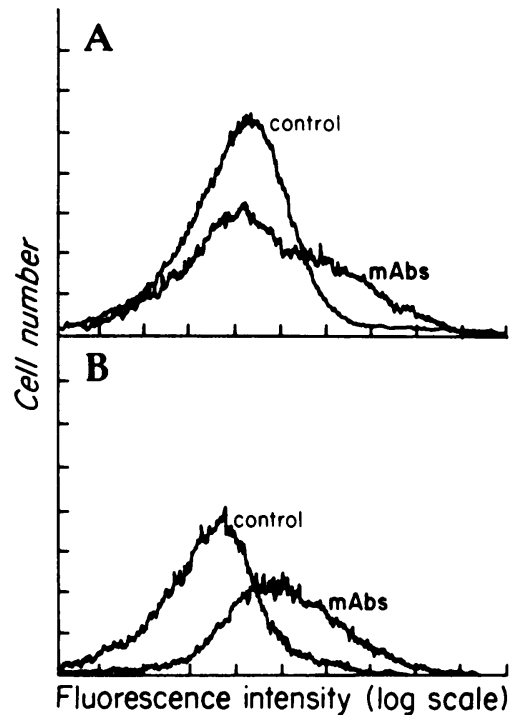

Figure 2. Flow cytometry studies with marrow from cat 65707. Marrow mononuclear cells obtained 4 wk $(A)$ or 11 wk $(B)$ after FeLV-C inoculation were incubated with alpha medium (control studies) or with monoclonal antibodies (mAbs) C11D8 and G13D8, which label distinct epitopes of gp70.

BFU-E, and CFU-GM were preferentially found in this fraction. When this cat was studied 7 wk later (Fig. $2 B$ ), the fluorescence distribution was similar to that of cats with PRCA (Fig. 1). These data suggest that most marrow cells were infected at this time. Cell sorting demonstrated that hematopoietic progenitors were among these positive cells (data not shown).

$C^{\prime}$ lysis studies. $C^{\prime}$ lysis studies were done to confirm that hematopoietic progenitors were infected with FeLV-C, and data representative of studies in four cats with PRCA are presented in Table II. When marrow cells were incubated with the monoclonal antibodies to gp70 and baby rabbit serum as a source of $\mathrm{C}^{\prime}$, their colony-forming ability was significantly decreased, confirming that BFU-E and CFU-GM were infected with retrovirus. In addition, the numbers of detectable BFU-E fell with exposure to the $C^{\prime}$ alone. This result suggested that BFU-E had an enhanced sensitivity to $C^{\prime}$-mediated lysis.

In additional studies, when PRCA marrow was incubated

Table I. FACS Studies with Monoclonal Antibodies (C11D8, G13D8) to gp70

\begin{tabular}{|c|c|c|c|c|c|c|}
\hline Cat no. & First antibodies & Sort* & Percent of cells & CFU-E & BFU-E & CFU-GM \\
\hline \multirow[t]{3}{*}{64977} & C11D8 & + & 38 & $0^{\ddagger}$ & $18 \pm 9$ & $40 \pm 6$ \\
\hline & C11D8 & - & 57 & 0 & 0 & $5 \pm 1$ \\
\hline & I9B4 & - & 99 & 0 & $8 \pm 1$ & $35 \pm 3$ \\
\hline \multirow[t]{5}{*}{64550} & C11D8 and G13D8 & + & 14 & $0^{8}$ & $104 \pm 4$ & $26 \pm 1$ \\
\hline & C11D8 and G13D8 & - & 84 & 0 & $50 \pm 2$ & $19 \pm 1$ \\
\hline & Alpha medium & - & 99 & 0 & $56 \pm 6$ & $18 \pm 1$ \\
\hline & Alpha medium & & Top $14 \%$ of distribution & 0 & $25 \pm 3$ & $15 \pm 2$ \\
\hline & Alpha medium & & Bottom $84 \%$ of distribution & 0 & $52 \pm 5$ & $24 \pm 1$ \\
\hline \multirow[t]{3}{*}{65707} & C11D8 and G13D8 & + & 20 & $55 \pm 3^{5}$ & $36 \pm 3$ & $21 \pm 4$ \\
\hline & C11D8 and G13D8 & - & 80 & $1 \pm 1$ & $4 \pm 1$ & $2 \pm 1$ \\
\hline & Alpha medium & - & 95 & $14 \pm 2$ & $14 \pm 2$ & $11 \pm 2$ \\
\hline
\end{tabular}

\footnotetext{
* For studies in cats 64977 and 64550 with PRCA, the cutoff was determined such that $1 \%$ of PRCA marrow cells treated with the irrelevant
} first antibody 19B4 or alpha medium would be positive. For marrow from cat 65707, studied 4 wk after FeLV-C inoculation, a 5\% cutoff was used. ‡ Progenitors (mean \pm SE) detected per $10^{5}$ marrow mononuclear cells plated with $30 \% \triangle F C S$.

Progenitors (mean \pm SE) detected per $2.5 \times 10^{4}$ marrow mononuclear cells plated with $20 \% \Delta \mathrm{FCS}$ and $10 \% \Delta$ cat serum (8). 
Table II. C' Lysis Studies with Monoclonal Antibodies (C11D8, G13D8) to gp70

\begin{tabular}{|c|c|c|c|}
\hline & CFU-E & BFU-E & CFU-GM \\
\hline \multicolumn{4}{|l|}{ PRCA marrow } \\
\hline$\Delta \mathrm{FCS} / \Delta \mathrm{FCS}^{*}$ & $0^{\ddagger}$ & $83 \pm 4$ & $34 \pm 2$ \\
\hline$\Delta \mathrm{FCS} / \mathrm{C}^{\prime}$ & 0 & $51 \pm 5$ & $33 \pm 2$ \\
\hline Abs to $\mathrm{gp} 70 / \Delta \mathrm{FCS}$ & 0 & $80 \pm 3$ & $35 \pm 4$ \\
\hline Abs to $\mathrm{gp} 70 / \mathrm{C}^{\prime}$ & 0 & $21 \pm 2$ & $18 \pm 2$ \\
\hline \multicolumn{4}{|l|}{ Normal marrow } \\
\hline$\Delta \mathrm{FCS} / \Delta \mathrm{FCS}$ & $425 \pm 15$ & $145 \pm 2$ & $41 \pm 1$ \\
\hline$\Delta \mathrm{FCS} / \mathrm{C}^{\prime}$ & $384 \pm 6$ & $142 \pm 4$ & $38 \pm 2$ \\
\hline Abs to $\mathrm{gp} 70 / \triangle \mathrm{FCS}$ & $373 \pm 26$ & $148 \pm 7$ & $42 \pm 3$ \\
\hline Abs to $\mathrm{gp} 70 / \mathrm{C}^{\prime}$ & $389 \pm 5$ & $138 \pm 3$ & $40 \pm 3$ \\
\hline \multicolumn{4}{|c|}{$\begin{array}{l}\text { Marrow from a cat } \\
\text { viremic with FeLV-C }\end{array}$} \\
\hline$\Delta \mathrm{FCS} / \triangle \mathrm{FCS}$ & $217 \pm 7$ & $83 \pm 4$ & $36 \pm 2$ \\
\hline$\Delta \mathrm{FCS} / \mathrm{C}^{\prime}$ & $206 \pm 13$ & $12 \pm 2$ & $35 \pm 2$ \\
\hline Abs to $\mathrm{gp} 70 / \Delta \mathrm{FCS}$ & $216 \pm 13$ & $83 \pm 2$ & $33 \pm 2$ \\
\hline Abs to $\mathrm{gp} 70 / \mathrm{C}^{\prime}$ & $24 \pm 6$ & $2 \pm 1$ & $6 \pm 1$ \\
\hline
\end{tabular}

Abs, Antibodies.

* Marrow was incubated with $\triangle \mathrm{FCS}$ for $60 \mathrm{~min}$ at room temperature, then with $\triangle \mathrm{FCS}$ for $60 \mathrm{~min}$ at $37^{\circ} \mathrm{C}$, and then washed once before plating in methylcellulose culture. See text for details.

${ }^{\ddagger}$ Progenitors (mean \pm SE) detected per input of $10^{5}$ marrow mononuclear cells.

with baby rabbit serum as a source of $C^{\prime}$, the mean $( \pm S E)$ number of BFU-E detected in vitro was $47 \pm 5 \%$ of the number of BFU-E detected when marrow was incubated with $\triangle F C S$ (17 experiments). In contrast, $98 \pm 3 \%$ of baseline BFU-E were detected after the treatment of normal cat marrow with $C^{\prime}(16$ experiments in eight cats). The recoveries of CFU-GM after exposure of PRCA or normal marrow cells to $C^{\prime}$ were $92 \pm 2$ and $97 \pm 2 \%$, respectively.

Although the results of FACS analysis suggest that hematopoietic progenitors from cat 65707 were infected before week 4 after inoculation with FeLV-C (Table I), C' lysis studies did not demonstrate infection until week 10 (data not shown). At this time, BFU-E first appeared sensitive to $C^{\prime}$.

Five studies in two cats that were viremic but had not yet developed anemia also demonstrated that CFU-E, like CFUGM, were infected but were not unusually sensitive to $\mathrm{C}^{\prime}$ (Table II).

When cultures of marrow cells from a cat with PRCA were examined daily, colonies containing hemoglobinized cells appeared at day $5.74 \%$ of these erythroid bursts were $C^{\prime}$ sensitive. The cultures were then scored on days $6-12$, and the percentages of erythroid bursts sensitive to $C^{\prime}$ were similar, and were $76,86,85,77$, and $82 \%$, respectively.

Characterization of the $C^{\prime}$ sensitivity of BFU-E. Several studies were undertaken to confirm that the decrease in BFU-E detected after incubation with baby rabbit serum represented enhanced $C^{\prime}$ sensitivity rather than nonspecific toxicity of the serum. Data in Table III show that near baseline numbers of BFU-E were detected after incubation of PRCA marrow with heat-inactivated baby rabbit serum or serum treated with chelators (EDTA). When marrow was incubated
Table III. Characterization of the $C^{\prime}$ Sensitivity of Marrow BFU-E from Cats with PRCA

\begin{tabular}{|c|c|c|}
\hline & BFU-E & CFU-GM \\
\hline \multicolumn{3}{|l|}{ Control study } \\
\hline$\Delta \mathrm{FCS}$ & $116 \pm 10^{*}$ & $57 \pm 5$ \\
\hline \multicolumn{3}{|l|}{ Studies with baby rabbit serum } \\
\hline Baby rabbit serum & $27 \pm 4$ & $57 \pm 2$ \\
\hline$\Delta$ Baby rabbit serum & $93 \pm 7$ & $62 \pm 4$ \\
\hline Baby rabbit serum + EDTA ${ }^{\ddagger}$ & $88 \pm 4$ & $52 \pm 2$ \\
\hline Baby rabbit serum + EGTA $+\mathrm{MgCl}_{2}^{\S}$ & $112 \pm 5$ & $66 \pm 6$ \\
\hline \multicolumn{3}{|l|}{ Studies with guinea pig serum } \\
\hline Guinea pig serum & $45 \pm 4$ & $47 \pm 3$ \\
\hline$\Delta$ Guinea pig serum & $122 \pm 8$ & $51 \pm 3$ \\
\hline Guinea pig serum + EDTA $^{\ddagger}$ & $79 \pm 5$ & $41 \pm 2$ \\
\hline Guinea pig serum + EGTA $+\mathrm{MgCl}_{2}^{\S}$ & $98 \pm 7$ & $57 \pm 3$ \\
\hline C4-deficient guinea pig serum & $95 \pm 10$ & $52 \pm 3$ \\
\hline \multicolumn{3}{|l|}{ Studies with cat serum } \\
\hline Cat serum & $115 \pm 5$ & $61 \pm 3$ \\
\hline
\end{tabular}

* Progenitors (mean $\pm \mathrm{SE}$ ) detected per input of $10^{5}$ marrow mononuclear cells. Marrow cells were incubated for $1 \mathrm{~h}$ at $37^{\circ} \mathrm{C}$ with fresh or heat-inactivated $(\Delta)$ serum, and then washed before plating in methylcellulose. Similar results were obtained in two additional studies. ${ }^{\ddagger}$ EDTA inhibits complement activation by both the classical and alternate pathways.

${ }^{8}$ EGTA with $\mathrm{MgCl}_{2}$ inhibits complement activation only via the classical pathway.

with baby rabbit serum, EGTA and $\mathrm{MgCl}_{2}$, a baseline number of BFU-E persisted, suggesting that $C^{\prime}$ was activated by the classical pathway. Similar results were obtained with guinea pig serum (Table III). In addition, incubation of PRCA marrow with C4-deficient guinea pig serum did not inhibit BFU-E growth, confirming that the $C^{\prime}$ effect was mediated via the classical pathway. Our results could not be reproduced with fresh cat serum as a $C^{\prime}$ source (Table III). Similarly, exposure of PRCA marrow to a low ionic strength sucrose solution with $5 \%$ fresh cat serum (sucrose hemolysis test) or to acidified fresh serum (Ham test) did not decrease the number of detectable BFU-E (data not shown).

In other studies, marrow from a cat with PRCA was incubated for $0,30,60,90$, or 120 min with baby rabbit serum. At each of these time points, respectively, $62 \pm 3$ (mean $\pm S E$ ), $34 \pm 2,27 \pm 1,22 \pm 2$, and $18 \pm 2$ BFU-E were detected; the numbers of CFU-GM detected, however, remained unchanged ( $17 \pm 2$ at baseline and $16 \pm 1$ at $120 \mathrm{~min}$ ). In a separate experiment, marrow from a viremic cat was studied after a 4-h exposure to baby rabbit serum or $\triangle F C S$. With $\triangle F C S, 187 \pm 7$ BFU-E and $50 \pm 4$ CFU-GM were detected. After $4 \mathrm{~h}$ of $\mathrm{C}^{\prime}$ exposure, $6 \pm 1$ BFU-E and 58 \pm 7 CFU-GM remained, confirming the resistance of CFU-GM to in vitro $C^{\prime}$ lysis.

Studies were undertaken to determine if BFU-E infected with FeLV-C were uniquely sensitive to $C^{\prime}$ lysis or if this was a general property of retrovirus-infected BFU-E or BFU-E with accelerated cell cycle kinetics. Representative studies, shown in Table IV, indicated that neither increased cell cycle kinetics nor evidence of progenitor infection with the Rickard strain of FeLV or FeLV-A/Glasgow-1 was associated with an increased $C^{\prime}$ sensitivity of BFU-E. 
Table IV. Correlation of Cell Cycle Kinetics and Retrovirus Infection with Sensitivity of BFU-E to C' Lysis

\begin{tabular}{|c|c|c|c|c|c|}
\hline & HCT & $\begin{array}{l}\text { Percent BFU-E } \\
\text { in DNA synthesis* }\end{array}$ & $\begin{array}{l}\text { Number of BFU-E } \\
\text { in control cultures }\end{array}$ & $\begin{array}{l}\text { Number of BFU-E } \\
\text { after exposure to } C^{\prime}\end{array}$ & $\begin{array}{l}\text { Number of BFU-E } \\
\text { after exposure to antibodies } \\
\text { to gp70 then } C^{\prime}\end{array}$ \\
\hline & $\%$ & & & & \\
\hline Normal $^{\ddagger}$ & 38 & 23 & $138 \pm 3^{\prime \prime}$ & $138 \pm 5$ & $139 \pm 3$ \\
\hline Phenylhydrazine and phlebotomy ${ }^{\ddagger}$ & 20 & 46 & $80 \pm 3$ & $78 \pm 2$ & $74 \pm 6$ \\
\hline FeLV-A/Glasgow-1 $1^{8}$ & 37 & - & $128 \pm 5$ & $121 \pm 11$ & $68 \pm 5$ \\
\hline Rickard strain of FeLV & 40 & 15 & $106 \pm 6$ & $102 \pm 2$ & $68 \pm 3$ \\
\hline PRCA & 14 & 42 & $114 \pm 4$ & $41 \pm 1$ & $8 \pm 1$ \\
\hline
\end{tabular}

* Determined by tritiated thymidine suicide experiments. ${ }^{\ddagger}$ Baseline studies were obtained in a normal cat and repeated 2 wk after phenylhydrazine treatment $\left(50 \mathrm{mg} / \mathrm{kg}\right.$ i.p.) and phlebotomy. ${ }^{8}$ Data are representative of six experiments in two cats $16-31$ wk after viral inoculation.

" Progenitors (mean $\pm \mathrm{SE}$ ) detected per input of $10^{5}$ marrow mononuclear cells.

Suspension culture studies. Suspension cultures of marrow from cats with PRCA were used to determine if progenitors less differentiated than BFU-E were also $C^{\prime}$ sensitive and infected. A representative study is shown in Table V. Pretreatment of marrow with $C^{\prime}$ or monoclonal antibodies to gp70 then $C^{\prime}$ decreased the number of BFU-E that were placed in suspension culture. However, after $2 \mathrm{~d}$ of suspension culture, nearly as many BFU-E were detected in cultures from marrow treated on day 0 with $C^{\prime}$ as were detected in control cultures treated day 0 with $\triangle F C S$, suggesting that BFU-E were recruited from an earlier population that was not sensitive to $C^{\prime}$. In contrast, the numbers of BFU-E remained low in cultures of marrow treated on day 0 with antibodies to $g p 70$ then $C^{\prime}$. These studies indicate that although earlier erythroid progenitors are infected with retrovirus, $\mathrm{C}^{\prime}$ sensitivity develops at the BFU-E stage of differentiation.

Studies of gp70 binding to normal progenitors. Additional studies were designed to confirm that the gp70 present on the surface on progenitor cells resulted from retroviral infection and not from the nonspecific adsorption of FeLV, FeLV protein, or immune complexes present in the serum of cats with PRCA. As shown in Table VI, after incubation of normal marrow with PRCA sera, gp70 could not be detected on the surface of progenitor cells with the $C^{\prime}$ lysis assay. However, when studies were performed with supernatant from FEA infected with FeLV-C, gp70 was detected on CFU-E and BFU-E, but not on CFU-GM. As binding persisted at $4^{\circ} \mathrm{C}$ and with heat inactivation of virus, these studies suggest that normal erythroid (but not granulocyte-macrophage) progenitors express a receptor specific for gp70. Similar results were obtained when normal marrow was incubated with supernatant from FEA infected with FeLV-A/Glasgow-1 (data not shown).

In additional studies it was determined if binding of $\mathrm{gp} 70$ or FeLV-C alone were sufficient to render BFU-E sensitive to $\mathrm{C}^{\prime}$ lysis. Because others have reported the human and cat (but not rabbit) serum may bind directly to the transmembrane envelope protein $\mathrm{p} 15 \mathrm{E}$ of several retroviruses $(17,18)$, normal marrow cells initially treated with FeLV-C were then incubated with $\triangle \mathrm{FCS}$, fresh human serum, or fresh normal cat serum as well as baby rabbit serum. The results of these studies (data not shown) failed to demonstrate a relationship between the presence of FeLV-C or viral protein on BFU-E and $C^{\prime}$ sensitivity, and therefore suggest that $C^{\prime}$ sensitivity reflects progenitor infection and disease progression.

\section{Discussion}

Many viruses, including hepatitis, Epstein-Barr virus, and parvovirus, have been associated with erythroid marrow failure; and $T$ cell-mediated inhibition of erythropoiesis, aberrant antibody formation, and direct viral infection of erythroid progenitors have been suggested as the mechanisms underlying

Table V. Suspension Culture Studies of Marrow Cells in PRCA

\begin{tabular}{|c|c|c|c|c|c|c|c|c|c|}
\hline & \multicolumn{3}{|c|}{ CFU-E } & \multicolumn{3}{|l|}{ BFU-E } & \multicolumn{3}{|c|}{ CFU-GM } \\
\hline & Input & Day 2 & $\begin{array}{l}\text { Number } \\
\text { generated }\end{array}$ & Input & Day 2 & $\begin{array}{l}\text { Number } \\
\text { generated }\end{array}$ & Input & Day 2 & $\begin{array}{l}\text { Number } \\
\text { generated }\end{array}$ \\
\hline \multicolumn{10}{|l|}{ Initial treatment } \\
\hline$\Delta \mathrm{FCS} / \Delta \mathrm{FCS}{ }^{*}$ & 0 & 0 & 0 & $38 \pm 4^{\ddagger}$ & $131 \pm 6$ & $93-131^{5}$ & $28 \pm 1$ & $54 \pm 2$ & $26-54$ \\
\hline$\Delta \mathrm{FCS} / \mathrm{C}^{\prime}$ & 0 & 0 & 0 & $20 \pm 1$ & $113 \pm 8$ & $93-113$ & $30 \pm 4$ & $55 \pm 2$ & $25-55$ \\
\hline Abs to $\mathrm{gp} 70 / \triangle \mathrm{FCS}$ & 0 & $\mathbf{0}$ & $\mathbf{0}$ & $37 \pm 3$ & $127 \pm 8$ & $90-127$ & $32 \pm 2$ & $53 \pm 4$ & $21-53$ \\
\hline Abs to $\mathrm{gp} 70 / \mathrm{C}^{\prime}$ & 0 & 0 & 0 & $5 \pm 1$ & $11 \pm 2$ & $6-11$ & $12 \pm 2$ & $24 \pm 1$ & $12-24$ \\
\hline
\end{tabular}

Abs, Antibodies. "Marrow was incubated with $\triangle \mathrm{FCS}$ for $60 \mathrm{~min}$ at room temperature, then $\triangle \mathrm{FCS}$ for $60 \mathrm{~min}$ at $37^{\circ} \mathrm{C}$, then washed and resuspended to the initial volume before plating in methylcellulose. ${ }^{\ddagger}$ Progenitors (mean \pm SE) detected per input of $5 \times 10^{4}$ marrow mononuclear cells. Data represent six experiments in two cats with PRCA. The minimum value assumes all progenitors initially present were maintained during $2 \mathrm{~d}$ of suspension culture. The maximum value assumes these progenitors differentiated or died during this time interval. 
Table VI. Studies of gp70 Binding to Normal Marrow

\begin{tabular}{|c|c|c|c|c|c|}
\hline $\begin{array}{l}\text { First incubation } \\
\left(37^{\circ} \mathrm{C}, 1 \mathrm{~h}\right)^{*}\end{array}$ & $\begin{array}{l}\text { Second incubation } \\
\left(20^{\circ} \mathrm{C}, 1 \mathrm{~h}\right)\end{array}$ & $\begin{array}{l}\text { Third incubation } \\
\left(37^{\circ} \mathrm{C}, 1 \mathrm{~h}\right)\end{array}$ & CFU-E & BFU-E & CFU-GM \\
\hline FEA $^{\ddagger}$ & Abs to gp70 & $\mathrm{C}^{\prime}$ & $282 \pm 13^{\S}$ & $91 \pm 6$ & $61 \pm 5$ \\
\hline FeLV-C & $\Delta \mathrm{FCS}$ & $\mathbf{C}^{\prime}$ & $335 \pm 23$ & $82 \pm 1$ & $51 \pm 5$ \\
\hline FeLV-C & Abs to gp70 & $\mathbf{C}^{\prime}$ & $77 \pm 7$ & $3 \pm 1$ & $59 \pm 3$ \\
\hline FeLV-C $\left(4^{\circ} \mathrm{C}\right)$ & Abs to gp70 & $\mathbf{C}^{\prime}$ & $64 \pm 7$ & $1 \pm 1$ & $50 \pm 4$ \\
\hline$\Delta$ FeLV-C & Abs to gp70 & $\mathbf{C}^{\prime}$ & $87 \pm 1$ & $2 \pm 1$ & $62 \pm 4$ \\
\hline PRCA serum No. 1 & Abs to gp70 & $\mathbf{C}^{\prime}$ & $293 \pm 20$ & $101 \pm 8$ & $57 \pm 4$ \\
\hline PRCA serum No. 1 & $\Delta \mathrm{FCS}$ & $\mathbf{C}^{\prime}$ & $273 \pm 33$ & $109 \pm 6$ & $62 \pm 6$ \\
\hline PRCA serum No. 2 & Abs to gp70 & $\mathbf{C}^{\prime}$ & $288 \pm 29$ & $70 \pm 1$ & $63 \pm 5$ \\
\hline PRCA serum No. 2 & $\Delta \mathrm{FCS}$ & $\mathbf{C}^{\prime}$ & $345 \pm 25$ & $87 \pm 7$ & $58 \pm 5$ \\
\hline
\end{tabular}

Abs, Antibodies. * See text for details. ${ }^{\ddagger}$ FEA (supernatant from FEA); FeLV-C (supernatant from FEA infected with FeLV-C). ${ }^{\S}$ Progenitors (mean $\pm \mathrm{SE}$ ) detected per input of $10^{5}$ marrow mononuclear cells. Equivalent results were obtained in three additional studies. $\Delta \mathrm{FeLV}-\mathrm{C}$, heat-inactivated FeLV-C.

the marrow failure in individual patients $(19,20)$. Although parvovirus infects hematopoietic stem cells, it is a DNA tumor virus with a different replication strategy from FeLV. Studies with parvovirus have demonstrated that erythroid progenitors, but presumbably not granulocytic progenitors, are infected, leading to BFU-E lysis and resulting in PRCA (21-23). To assess if a similar mechanism could induce selective erythroid failure in cats, we investigated if red cell progenitors were uniquely infected with FeLV-C.

As hematopoietic progenitors generally comprise $<0.5 \%$ of marrow mononuclear cells, it is difficult to assess infection directly. Two strategies are possible. First, one may look for the presence of virus or viral protein in colonies derived from hematopoietic progenitor cells. With this approach, however, one cannot exclude the possibility that cells were infected while differentiating in vitro. This is of particular concern with FeLV as others have demonstrated using heterologous antisera directed at gag-related, viral core proteins, that circulating granulocytes and most marrow cells, including recognizable granulocyte progenitors, are infected (16).

A second strategy is to look for the presence of viral envelope proteins on the surface of progenitor cells with FACS or $\mathrm{C}^{\prime}$ lysis studies. If cells express gp70, one may infer that provirus is integrated into the genome, and that after the transcription and translation of viral sequences, envelope protein is incorporated into the host cell membrane. This approach has been used to demonstrate that Friend virus complex infects murine CFU-GM (24).

Our FACS and $C^{\prime}$ lysis studies with monoclonal antibodies C11D8 and G13D8 demonstrated that BFU-E, CFU-E, and CFU-GM from cats viremic with FeLV-C expressed gp70. Data from 2-d suspension cultures also suggested that earlier hematopoietic progenitors were productively infected with FeLV, consistent with the experience with murine retroviruses that have been used as vectors to incorporate foreign material into multipotent hematopoietic stem cells $(25,26)$.

A potential concern in interpretation of these data is that gp70 present in the serum of viremic cats could nonspecifically bind to hematopoietic progenitors and, if so, the presence of gp70 on the surface of cells might not reflect the productive infection of that cell with retrovirus. To test this hypothesis directly, we incubated normal cat marrow with virus and viral protein under optimal conditions for nonspecific binding. After this incubation, gp70 could be detected on erythroid but not granulocyte-macrophage progenitor cells (Table VI). When marrow cells were incubated at $4^{\circ} \mathrm{C}$ with virus and then extensively washed before study, gp70 was also detected on erythroid progenitors with the $C^{\prime}$ lysis assay, suggesting that the glycoprotein binds to a specific receptor. As the binding of gp70 to a cell surface receptor is the mode by which a retrovirus infects a cell, these data raise the possibilities that erythroid progenitors are more susceptible than granulocytic progenitors to retroviral infection, or that more viral proteins may be present on the surface of committed erythroid cells. The relationship of this finding to the pathogenesis of feline PRCA is speculative.

As the concentrations of FeLV-C, viral proteins, or immune complex present in the sera of cats with PRCA are insufficient to result in detectable gp70 binding to normal erythroid progenitors (Table VI), the results of our studies of viremic cat marrow are most consistent with the conclusion that erythroid progenitors are productively infected with retrovirus. It is possible, however, that the binding of FeLV-C to progenitors is dependent on the local production of retrovirus by marrow cells and not the serum virus concentration. More importantly, as CFU-GM from normal cats do not bind exogenous gp70, our studies clearly demonstrate that these progenitors from cats viremic with FeLV-C are infected and that infection occurs as early as $4 \mathrm{wk}$ after viral inoculation. Hence, the infection of erythroid progenitors, per se, is not the cause of feline PRCA.

In confirming our FACS studies with $\mathrm{C}^{\prime}$ lysis experiments, we observed that BFU-E from cats with PRCA were unusually sensitive in vitro to the lytic action of heterologous $C^{\prime}$ alone. This enhanced sensitivity appeared to result from $\mathrm{C}^{\prime}$ activation via the classical pathway. Further studies indicated that $C^{\prime}$ sensitivity was not a property of CFU-E, CFU-GM, or progenitors that were capable of giving rise to BFU-E in suspension culture.

In addition, we determined if $\mathrm{C}^{\prime}$ sensitivity was a property of BFU-E with altered cell cycle kinetics. Our previous studies using tritiated thymidine demonstrated that after FeLV-C infection, $43 \pm 4 \%$ (SD) of BFU-E are in DNA synthesis (normal $23 \pm 2 \%$ ), while the cell cycle kinetics of CFU-GM are normal 
(8). Thus, we investigated if BFU-E in rapid cell cycle after phenylhydrazine and phlebotomy were sensitive to $C^{\prime}$ lysis. Although BFU-E were activated into cell cycle as a result of the anemia (46\% in DNA synthesis), there was no evidence of increased $C^{\prime}$ sensitivity.

The Rickard strain of FeLV induces a thymic lymphosarcoma, and not anemia (16). Our studies of marrow from a cat viremic with Rickard-FeLV (Table IV) indicated that hematopoietic progenitors are infected but not sensitive to $C^{\prime}$. Similar results were obtained in studies of marrow from cats viremic with FeLV-A/Glasgow-1 (Table IV). Therefore, $\mathrm{C}^{\prime}$ sensitivity is not a general property of retrovirus-infected BFU-E.

There are several mechanisms that might explain the unusual $C^{\prime}$ sensitivity of BFU-E from cats viremic with FeLV-C. First, antibody to viral protein and/or a BFU-E membrane determinant may be present in the serum of viremic cats and bind to BFU-E in vivo, causing the progenitor to be sensitive to $C^{\prime}$ in vitro. Our initial co-culture studies of PRCA serum with autologous or normal marrow did not support this premise (7).

Second, cat Clq might bind directly to a viral envelope protein on the BFU-E membrane and initiate $\mathrm{C}^{\prime}$ activation. Others have reported that feline or human Clq can bind directly to the p15E of several retroviruses, resulting in $C^{\prime}$ activation and viral lysis $(17,18,27,28)$. Although intact virus may be lysed by this mechanism, direct $C^{\prime}$ activation by virally infected nucleated cells has not been reported (28). For BFU-E to be detected in culture, they must mature and differentiate to hemoglobinized cells. Therefore, one possibility, consistent with our results and with the finding of normal frequencies of BFU-E in marrow of cats with PRCA, is that $C^{\prime}$ does not lyse cells but, rather, damages the membrane in such a way that BFU-E differentiation is specifically impaired.

Third, FeLV-C infection alone could somehow alter the BFU-E cell membrane and lead to increased $C^{\prime}$ sensitivity. In considering this mechanism, it is tempting to draw parallels with the $C^{\prime}$ sensitivity of BFU-E in feline PRCA and PNH in man. PNH is a clonal disorder of the hematopoietic stem cell that classically presents as hemolysis with hemoglobinuria, but may be associated with pancytopenia (29-31). PNH erythrocytes lack acetylcholinesterase on their surface (32) and circulating cells are $C^{\prime}$ sensitive (33). Demonstration of $C^{\prime}$ sensitivity requires the exposure of PNH cells to acidified serum (12) or to serum in the presence of a low ionic strength sucrose solution (13). These manipulations further activate the alternate and classical $C^{\prime}$ pathways, respectively. Some studies (34) suggest that BFU-E from patients with $\mathrm{PNH}$ are $\mathrm{C}^{\prime}$ sensitive, while others (35) demonstrate that the defect is acquired subsequently during maturation towards red cells. It is thought that the absence of decay-accelerating factor is responsible for decreased $\mathrm{C} 3 \mathrm{~b}$ convertase activity, and leads to the increased stability of $\mathrm{C} 3 \mathrm{~b}$ and increased $\mathrm{C}^{\prime}$ activation $(33,36,37)$. In contrast to PNH, our studies in glucose-6-phosphate dehydrogenase heterozygous cats have demonstrated that feline PRCA is not a clonal disorder of the myeloid stem cell (6). Complement activation is via the classical, and not the alternate, pathway. We could not demonstrate sensitivity of marrow progenitors to acidified cat serum or to a low ionic strength sucrose solution. The possible lysis of differentiated cells was not studied with these assays.

As our studies with heterologous $C^{\prime}$ could not be repeated with fresh cat serum as the $\mathrm{C}^{\prime}$ source (Table III), the relevance of our studies to pathogenesis of PRCA in vivo is more difficult to assess. However, Grant et al. (38) have reported that cat $\mathrm{C}^{\prime}$ is uniquely slow in its action, requiring 8-20 h for lysis of antibody-coated cells.

We hypothesize, therefore, that feline PRCA results from the $C^{\prime}$ sensitivity of retrovirus-infected BFU-E. As cats with PRCA have normal numbers of BFU-E, and no detectable CFU-E (6), it is this stage of differentiation that is impaired in vivo. It is of interest that cats in the community with FeLVassociated anemia have decreased levels of serum $C^{\prime}(39)$, which is consistent with the consumption of $\mathrm{C}^{\prime}$ proteins.

\section{Acknowledgments}

We would like to thank Drs. David Onions and Os Jarrett, University of Glasgow, Scotland, for providing uninfected FEA, FEA infected with FeLV-C/Sarma, and FEA infected with FeLV-A/Glasgow-1; Dr. Edward Hoover, Colorado State University, Fort Collins, CO, for the Rickard strain of FeLV; Ms. Judee Reel for help in preparation of the manuscript; and Dr. John Adamson for his constructive comments.

This work was supported by research grants HL 31823 from the National Heart, Lung and Blood Institute and CA 38845 from the National Cancer Institute of National Institutes of Health, Department of Health and Human Services. Dr. Abkowitz is the recipient of a Clinical Oncology Career Development Award from the American Cancer Society.

\section{References}

1. Hardy, W. D., Jr. 1980. Feline leukemia virus diseases. In Feline Leukemia Virus. W. D. Hardy, Jr., M. Essex, and A. J. McClelland, editors. Elsevier Science Publishing Co. Inc., New York. 3-31.

2. Maggio, L., R. Hoffman, S. M. Cotter, N. Dainiak, S. Mooney, and L. A. Maffei. 1978. Feline preleukemia: an animal model of human disease. Yale J. Biol. Med. 51:469-476.

3. Mullins, J. I., C. S. Chen, and E. A. Hoover. 1986. Disease-specific and tissue-specific production of unintegrated feline leukaemia virus variant DNA in feline AIDS. Nature (Lond.). 319:333-336.

4. Onions, D., O. Jarrett, N. Testa, F. Frassoni, and S. Toth. 1982. Selective effect of feline leukaemia virus on early erythroid precursors. Nature (Lond.). 296:156-158.

5. Testa, N. G., O. Onions, O. Jarrett, F. Frassoni, and J. F. Eliason. 1983. Haemopoietic colony formation (BFU-E, GM-CFC) during the development of pure red cell hypoplasia induced in the cat by feline leukaemia virus. Leuk. Res. 7:103-116.

6. Abkowitz, J. L., R. L. Ott, J. M. Nakamura, L. Steinmann, P. J. Fialkow, and J. W. Adamson. 1985. Feline glucose-6-phosphate dehydrogenase cellular mosaicism: application to the study of retrovirusinduced pure red cell aplasia. J. Clin. Invest. 75:133-140.

7. Abkowitz, J. L., R. L. Ott, R. D. Holly, and J. W. Adamson. 1987. Lymphocytes and antibody in retrovirus-induced feline pure red cell aplasia. J. Natl. Cancer Inst. 78:135-139.

8. Abkowitz, J. L., R. D. Holly, and J. W. Adamson. Retrovirusinduced feline pure red cell aplasia: the kinetics of erythroid marrow failure. J. Cell. Physiol. In press.

9. Abkowitz, J. L., R. D. Holly, G. M. Segal, and J. W. Adamson. 1986. Multilineage, non-species specific hematopoietic growth factor(s) elaborated by a feline fibroblast cell line: enhancement by virus infection. J. Cell. Physiol. 127:189-196.

10. Grant, C. K., B. J. Ernisse, O. Jarrett, and F. R. Jones. 1983. Feline leukemia virus envelope gp70 of subgroups $B$ and $C$ defined by monoclonal antibodies with cytotoxic and neutralizing functions. $J$. Immunol. 131:3042-3048.

11. Baker, P. J., and S. G. Osofsky. 1980. Activation of human complement by heat-killed human kidney cells grown in cell culture. $J$. Immunol. 124:81-86. 
12. Ham, T. H., and J. H. Dingle. 1939. Studies on destruction of red blood cells. II. Chronic hemolytic anemia with paroxysmal nocturnal hemoglobinuria: certain immunological aspects of the hemolytic mechanism with special reference to serum complement. J. Clin. Invest. 18:657-672.

13. Hartmann, R. C., and D. E. Jenkins, Jr. 1966. The "sugarwater" test for paroxysmal nocturnal hemoglobinuria. N. Engl. J. Med. 275:155-157.

14. Jarrett, O., M. C. Golder, S. Toth, D. E. Onions, and M. F. Stewart. 1984. Interaction between feline leukaemia virus subgroups in the pathogensis of erythroid hypoplasia. Int. J. Cancer. 34:283-288.

15. Rickard, C. G., J. E. Post, F. Noronha, and L. M. Barr. 1969. A transmissible virus-induced lymphocytic leukemia of the cat. J. Natl. Cancer Inst. 42:987-996.

16. Hoover, E. A., J. L. Rojko, and R. G. Olsen. 1981. Pathogenesis of feline leukemia virus infection. In Feline Leukemia. R. G. Olsen, editor. CRC Press, Inc., Boca Raton, FL. 31-51.

17. Welsh, R. M., Jr., F. C. Jensen, N. R. Cooper, and M. B. A. Oldstone. 1976. Inactivation and lysis of oncornaviruses by human serum. Virology. 74:432-440.

18. Bartholomew, R. M., A. F. Esser, and H. J. Muller-Eberhard. 1978. Lysis of oncornaviruses by human serum: isolation of the viral complement $(\mathrm{C} 1)$ receptor and identification as p15E. J. Exp. Med. 147:844-853.

19. Krantz, S. B., and E. N. Dessypris. 1985. Pure red cell aplasia. In Hematopoietic Stem Cells. D. W. Golde and F. Takaku, editors. Marcel Dekker, Inc., New York. 229-251.

20. Young, N., and P. Mortimer. 1984. Viruses and bone marrow failure. Blood. 63:729-737.

21. Mortimer, P. P., R. K. Humphries, J. G. Moore, R. H. Purcell, and N. S. Young. 1983. A human parvovirus-like virus inhibits haematopoietic colony formation in vitro. Nature (Lond.). 302:426-429.

22. Young, N. S., P. P. Mortimer, J. G. Moore, and R. K. Humphries. 1984. Characterization of a virus that causes transient aplastic crisis. J. Clin. Invest. 73:224-230.

23. Young, N., M. Harrison, J. Moore, P. Mortimer, and R. K. Humphries. 1984. Direct demonstration of the human parvovirus in erythroid progenitor cells infected in vitro. J. Clin. Invest. 74:20242032.

24. Marcelletti, J., and P. Furmanski. 1979. Infection of macrophages with Friend virus: relationship to the spontaneous regression of viral erythroleukemia. Cell. 16:649-659.

25. Dick, J. E., M. C. Magli, D. Huszar, R. A. Phillips, and A. Bernstein. 1985. Introduction of a selectable gene into primitive stem cells capable of long-term reconstitution of the hematopoietic system of $\mathrm{W} / \mathrm{W}^{\mathrm{v}}$ mice. Cell. 42:71-79.

26. Hock, R. A., and A. D. Miller. 1986. Retrovirus-mediated transfer and expression of drug resistance genes in human haematopoietic progenitor cells. Nature (Lond.). 320:275-277.

27. Cooper, N. R., F. C. Jensen, R. M. Welsh, Jr., and M. B. A. Oldstone. 1976. Lysis of RNA tumor viruses by human serum: direct antibody-independent triggering of the classical complement pathway. J. Exp. Med. 144:970-984.

28. Cooper, N. R., and G. R. Nemerow. 1983. Complement, viruses, and virus-infected cells. Springer Semin. Immunopathol. 6:327347.

29. Rosse, W. F. 1980. Paroxysmal nocturnal hemoglobinuria: present status and future prospects. West. J. Med. 132:219-227.

30. Oni, S. B., B. O. Osunkoya, and L. Luzzatto, 1970. Paroxysmal nocturnal hemoglobinuria: evidence for monoclonal origin of abnormal red cells. Blood. 36:145-152.

31. Lewis, S. M., and J. V. Dacie. 1967. The aplastic anaemia: paroxysmal nocturnal haemoglobinuria syndrome. Br. J. Haematol. 13:236-251.

32. Kunstling, T. R., and W. F. Rosse. 1969. Erythrocyte acetylcholinesterase deficiency in paroxysmal nocturnal hemoglobinuria (PNH): a comparison of the complement-sensitive and insensitive populations. Blood. 33:607-616.

33. Rosse, W. F., and C. J. Parker. 1985. Paroxysmal nocturnal haemoglobinuria. Clin. Haematol. 14:105-125.

34. Dessypris, E. N., D. A. Clark, L. C. McKee, Jr., and S. B. Krantz. 1983. Increased sensitivity to complement of erythroid and myeloid progenitors in paroxysmal nocturnal hemoglobinuria. $N$. Engl. J. Med. 309:690-693.

35. Moore, J. G., R. K. Humphries, M. M. Frank, and N. Young. 1986. Characterization of the hematopoietic defect in paroxysmal nocturnal hemoglobinuria. Exp. Hematol. 14:222-229.

36. Nicholson-Weller, A., J. P. March, S. I. Rosenfeld, and K. F. Austen. 1983. Affected erythrocytes of patients with paroxysmal noctural hemoglobinuria are deficient in the complement regulatory protein, decay accelerating factor. Proc. Natl. Acad. Sci. USA. 80:50665070.

37. Nicholson-Weller, A., D. B. Spicer, and K. F. Austen. 1985. Deficiency of the complement regulatory protein, "decay-accelerating factor," on membranes of granulocytes, monocytes, and platelets in paroxysmal nocturnal hemoglobinuria. N. Engl. J. Med. 312:10911097.

38. Grant, C. K., D. J. DeBoer, M. Essex, M. B. Worley, and J. Higgins. 1977. Antibodies from healthy cats exposed to feline leukemia virus lyse feline lymphoma cells slowly with cat complement. $J$. Immunol. 119:401-406.

39. Grant, C. K., D. K. Pickard, C. Ramaika, B. R. Madewell, and M. Essex. 1979. Complement and tumor antibody levels in cats, and changes associated with natural feline leukemia virus infection and malignant disease. Cancer Res. 39:75-81. 